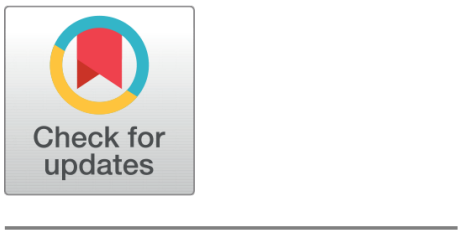

OPEN ACCESS

Received: 12.01.2021

Accepted: 15.05.2021

Published: 02.06 .2021

Citation: Madhuri J, Indiramma M (2021) Artificial Neural Networks Based Integrated Crop Recommendation System Using Soil and Climatic Parameters. Indian Journal of Science and Technology 14(19): 1587-1597. https://doi.org/ 10.17485/IJST/v14i19.64

* Corresponding author.

madhuri.bitcse@gmail.com

Funding: None

Competing Interests: None

Copyright: (c) 2021 Madhuri \& Indiramma. This is an open access article distributed under the terms of the Creative Commons Attribution License, which permits unrestricted use, distribution, and reproduction in any medium, provided the original author and source are credited.

Published By Indian Society for Education and Environment (iSee)

ISSN

Print: 0974-6846

Electronic: 0974-5645

\section{Artificial Neural Networks Based Integrated Crop Recommendation System Using Soil and Climatic Parameters}

\author{
J Madhuri ${ }^{1 *}$, M Indiramma ${ }^{2}$ \\ 1 Research Scholar, Department of Computer Science and Engineering, B.M.S. College of \\ Engineering, India \\ 2 Professor, Department of Computer Science and Engineering, B.M.S. College of \\ Engineering, India
}

\begin{abstract}
Objective : To develop crop recommendation system depending on location specific soil and climatic conditions. Method: The study introduces a novel recommendation system which uses Artificial Neural Networks (ANN) for recommending the suitable crop. The crops are recommended based on (a) Soil properties (b) Crop characteristics (c) Climate parameters. The crops namely maize, Finger millet, Rice and sugarcane is considered for the study. Depending on degree of relationship and limitations of the factors considered, following suitability classes are established: (a) Highly suitable: S1 (b) Moderately suitable: S2 (c) Marginally suitable: S3 (d) not suitable. The system uses the climate data from Meteorological survey of India and the soil data of Hadonahalli and Durgenahalli of Doddaballapur (dist.), Karnataka, India. The user interface developed takes the location specific soil properties as real time input and recommends the suitable crop considering the input and climate parameters. Findings: For the measurement of accuracy the model was tested on with ANN and decision tree. Overall accuracy value of ANN is $96 \%$ where the accuracy value of Decision tree is $91.5 \%$. Hence the results obtained from ANN can be considered more efficient. Novelty: The number of models developed for crop recommendation is limited and the proposed model serves as the promising aspect in the planning of crops.
\end{abstract}

Keywords: Crop recommendation; ANN; Soil characters; Climate; MongoDB

\section{Introduction}

India is one of the major producers of agricultural products across the world. The agricultural sector is the employment provider for $58 \%$ of the Indian population and its contribution to the GDP is $17 \%{ }^{(1)}$. Crop yield is dependent on the variety of attributes such as soil conditions, rainfall, available sunshine, irrigation, fertilizer application, pests, and land preparation. The common difficulty that Indian farmers face is that they do not opt for the crop according to the soil and climatic conditions ${ }^{(2)}$. Considering the fact that climate and soil properties have direct influence on crop yield, there is need to 
devise crop management practices based on soil and site suitability for maximizing production ${ }^{(3)}$. Predominantly weather and agriculture are strongly co-related and it is a necessity to embrace the changes in the climate patterns productively ${ }^{(4)}$. Climatesmart agriculture strategies is important to improve the yield and quality of yield. The previous researches ${ }^{(5)}$ summarizes the effect of extreme weather conditions on crops.

Lately the advent of precision agriculture presently has bought major changes in field of agriculture setting focus on irrigation methods, fertilizing, crop monitoring and yield prediction ${ }^{(6)}$. Incidentally choosing the suitable crop relative to location specific soil parameters and climatic conditions is important for increasing productivity. Hence farmers must be empowered with tools that enable them choose the right crop fitting location specific climatic and soil properties. Integrating machine learning for agricultural planning purposes is a promising approach in developing countries which has led to developing applications such as crop yield forecasting, crop disease identification, fertilizer management, and so on ${ }^{(2,7)}$. But the number of studies carried out in developing the recommendation system to choose the precise crop is limited. Developing the crop recommendation framework considering the location specific parameters will benefit the farmers. The work presented in this article aims at developing a recommendation model that suggests the most suitable crop depending on location-specific soil characteristics and climatic conditions. To the best of our knowledge no similar recommendation model using ANN has been reported.

The paper is organized as follows. Section 2 presents a literature survey of current web based and mobile based agricultural applications available, section 3 presents the proposed framework, section 4 describes the implementation details, section 5 discusses the experimental results.

\section{Related work}

Substantial amount of work has been carried out on impacts of climate and the soil on crop yield. Machine learning has unlimited potential in utilizing the historical climate dataset and demonstrate the linkages between climate and crop performance. It is the new scientific dimension that use data intense approaches to drive agricultural productivity. While Big Data handles massive amount of data generated from the farms by leveraging the technologies such as cloud computing and internet of things, machine learning techniques analyzes and supports decision making in smart farming ${ }^{(6)}$. Significant work has been carried out on yield forecasting using machine learning techniques. Studies indicate that considering the effects of climate of soil and climate parameters for the calculation of final yield is satisfactory ${ }^{(8)}$. Suggests novel applications of Machine Learning in agriculture can improve their operations, as algorithms can facilitate in classifying, clustering, detecting, and predicting different environmental conditions affecting agricultural operations and interpret the climate and weather-related risk in agriculture $^{(9)}$ proposes that combining machine learning with domain knowledge improves the conclusions about climate impact on agriculture. Artificial neural network (ANN) and multiple linear regression (MLR) has been used to predict biomass yield of winter wheat by identifying input features such as soil, precipitation, topographic, and management factors, the amount of (nitrogen, phosphorus, and potash) fertilizers consumed, and efficiency of water usage. The model has a determination coefficient $\mathrm{R}$ of $90 \%$ for the tillage method ${ }^{(10)}$. It is evident that soil and climate directly affect the yield, works related to recommending the crops depending on climate soil has been explored. The authors of ${ }^{(11)}$ proposes the crop model that suggests the suitable crops considering temperature, rainfall and soil $\mathrm{pH}$ applying decision trees and logistic regression. Data mining used in crop recommendation system chooses site specific soil parameters only. Using an ensemble model with random tree, CHAID, K-NN and naïve Bayes algorithms generates rules for recommendation ${ }^{(12)}$. The authors of ${ }^{(13)}$ uses decision tree, $\mathrm{K}-\mathrm{NN}$, random forest to demonstrate recommendation model considering soil type, precipitation, temperature is developed ${ }^{(14)}$. Incorporates soil and climate information for improving nitrogen recommendation for corn. Performance of eight different machine learning algorithms were observed on the dataset containing soil and weather variables. The performance of the algorithms were assessed based on their prediction of nitrogen fertilizer recommendation. Along with the adaptability of the crops to the environment, each crop species require specific soil - site conditions for optimum growth ${ }^{(15)}$. Based on the literature survey the shortcoming that we observed in these notable publications is that the authors have considered lesser experimental parameters for developing the recommendation model. In our work we have considered suitability of soil properties, climatic properties with calculated Evapotranspiration (Thornthwaite method). Our recommendation model is developed with Artificial Neural Networks and takes real time input to suggest the location specific suitable crop.

\section{Materials and methods}

The proposed framework builds a recommendation system that suggests a suitable crop by considering the physical properties of soil, climatic properties and crop characteristics. Choosing the right crop suitable to location specific conditions contributes to increase in crop yield ${ }^{(12)}$. This recommendation system empowers the farmers to decide a suitable crop for plantation. It also helps government agencies to device effective land management practices to increase productivity and maintain soil fertility. 
The proposed framework consists of four main stages as shown in Figure 1 The major steps followed in correlating soil and climate properties with crop requirements includes following steps:

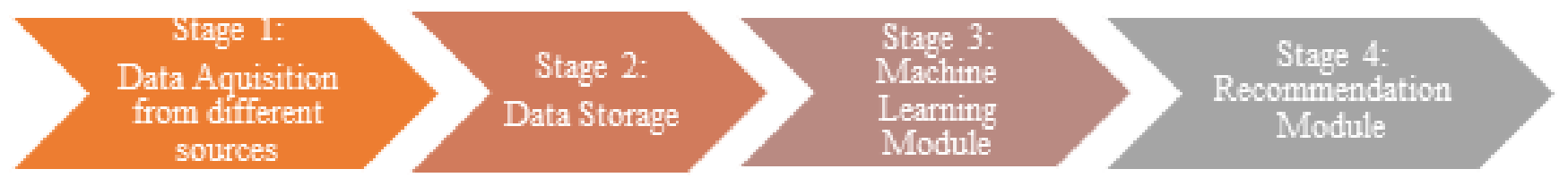

Fig 1. Proposed integrated crop recommendation framework

The data required for the study includes climate parameters, physical properties of soil and crop characteristics. Climate parameters are obtained from meteorological survey of India. The climate data is considered for the time span of 10 years (2007-2017). The crops namely maize, Finger millet, Rice and sugarcane is considered for the study. The crops considered are the important economics crops grown in the area. A document data store such as Mongo DB is the best option to store semi-structured data. Mongo DB is an open source document database that provides high availability, high performance and automatic scaling.

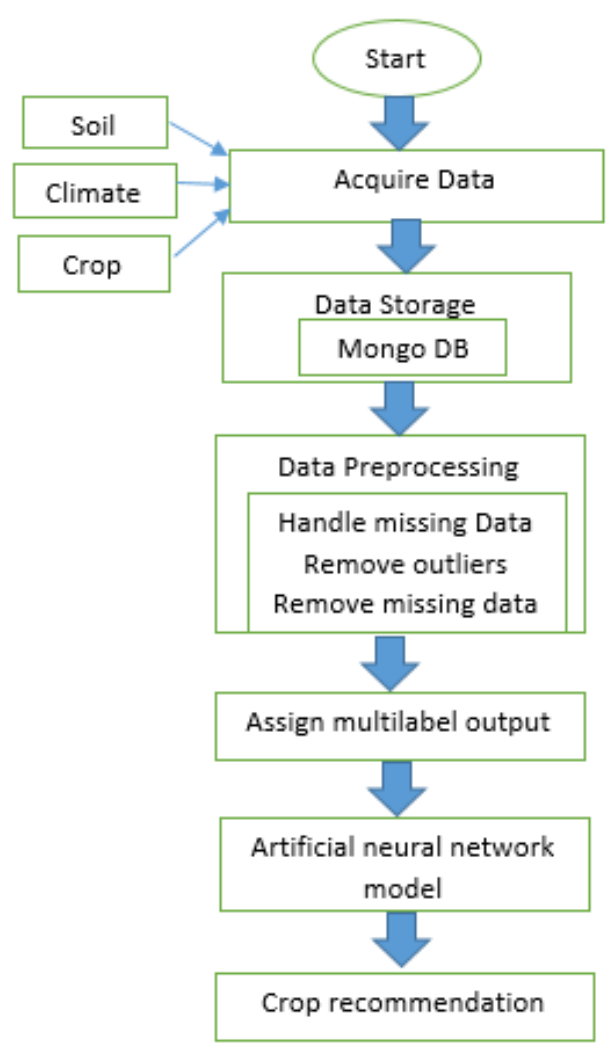

Fig 2. Methodology followed

Machine learning method used in the present study is artificial neural networks. Location specific crop is recommended based on the suitability measures namely: 1 . Highly suitable 2 . Moderately suitable 3 . Marginally suitable 4 . Not suitable. The detailed methodology followed in crop recommendation system is as shown in Figure 2. 


\subsection{Data set used}

In this study we focus on acquiring datasets for the locations Hadonahalli and Durgenahalli of Doddaballapur (dist.), Karnataka India The district lies at $13^{\circ} 20^{\prime}$ north latitude and $77^{\circ} 31^{\prime}$ east longitude. The data set consists of distinctive soil and climate characteristics together with crop requirements of maize, finger millet, sugarcane and rice. Unlike the standard weather parameters such as rainfall and temperature, other environmental aspects such as precipitation, humidity, wind speed, sunshine hours, potential evotranspiration is considered. Daily meteorological data for the location is collected from Agro meteorology Section, University of Agricultural Sciences, Bengaluru from the period 2007 to 2017. The land/ soil characteristics for this location is obtained from National Bureau of Soil Survey and Soil Usage Planning (NBSS \& LUP), Bengaluru. The soil dataset consists of 12 measures of soil physical properties. Among these measures, six attributes common and significant for crops has been considered ${ }^{(16)}$. The data of soil consists of texture, soil $\mathrm{pH}$, gravel code, erosion code and water retaining properties such as slope and depth. The soil parameters are indispensable for the crop growth. Even though their nutrient levels vary, soil efficiency directly effects the crop growth ${ }^{(17)}$. The crop requirement data consists of mean temperature, soil drainage, texture, depth, slope, length of growing period for every crop under study ${ }^{(3)}$.

Table 1. Dataset parameters and their description

\begin{tabular}{|c|c|c|}
\hline & Dataset parameter & Description \\
\hline 1 & Minimum Temperature & Lowest temperature recorded for the day. \\
\hline 2 & Maximum Temperature & Highest temperature recorded for the day. \\
\hline 3 & Sunshine hours & Total time during which the solar energy received is $75 \%$ of the maximum. \\
\hline 4 & Potential Evapotranspiration & Calculated from Thornthwaite ${ }^{(18,19)}$ Quantity of evaporation happening in the region. \\
\hline 5 & Soil texture & $\begin{array}{l}\text { Texture of the soil } \\
\text { 1. Clay } \\
\text { 2. Loamy sand } \\
\text { 3. Sandy loam } \\
\text { 4. Sandy clay loam } \\
\text { 5. Sandy clay loam } \\
\text { 6. Sandy }\end{array}$ \\
\hline 6 & Soil pH & Amount of acidity measured in soil \\
\hline 7 & Gravel code & $\begin{array}{l}\text { Indicates particle size in the soil } \\
\text { 1. Non gravel }(<15 \% \text { coarse }) \\
\text { 2. Gravelly }(15-35 \% \text { coarse })\end{array}$ \\
\hline 8 & Erosion code & $\begin{array}{l}\text { Amount of topsoil carried away due to wind and water } \\
\text { 1. Severe erosion } \\
\text { 2. Moderate erosion } \\
\text { 3. Slight erosion }\end{array}$ \\
\hline 9 & Slope & $\begin{array}{l}\text { Indicates the inclination of the soil surface relative to horizontal. } \\
\text { 1. Level to nearly level }(0-1 \%) \\
\text { 2. 10Very gently sloping }(1-3 \%) \\
\text { 3. Gently sloping }(3-5 \%) \\
\text { 4. Moderately sloping } 5-10 \%)\end{array}$ \\
\hline 10 & Depth & $\begin{array}{l}\text { Indicates the soil support required for shedding roots and absorption of water } \\
\text { 1. Shallow }(25-50 \mathrm{~cm}) \\
\text { 2. Deep }(100-150 \mathrm{~cm}) \\
\text { 3. Very deep }(>150 \mathrm{~cm})\end{array}$ \\
\hline 11 & Mean temperature & Average temperature required for the crop \\
\hline 12 & Soil drainage & Indicates the process where the water moves across, through or out of soil \\
\hline
\end{tabular}

\section{Potential Evapotranspiration (PET)}

Potential Evapotranspiration (PET) is extracted from the submitted data. PET is calculated using Thornthwaite method ${ }^{(18,19)}$. To calculate Potential Evapotranspiration (PET) using Thornthwaite method, the procedure is as follows:

$$
P E T_{\text {noncorrected }}=16 k\left(\frac{10 T}{i}\right)^{M}
$$


Where $\mathrm{i}$ is the monthly heat index, $\mathrm{T}$ is monthly temperature in degree Celsius.

Monthly heat index is calculated as follows:

$$
i=\left(\frac{T}{5}\right)^{1.514}
$$

Obtained values are later corrected according to the real length of the month and the theoretical sunshine hours as follows:

$$
P E T=P E T_{\text {noncorrected }} * \frac{N}{2} * \frac{d}{30}
$$

Where $\mathrm{N}$ : are the theoretical sunshine hours for each month and d number of days for each month.

\subsection{Data storage}

Component used for data storage is Mongo DB. Mongo DB is the high performance document oriented NoSQL database. Mongo DB is developed by Mongo DB Inc. and licensed under the Server Side Public License (SSPL). Contrary to traditional databases with rows and columns, Mongo DB uses collection of documents. Data is stored as JSON or BSON formats. A document stored in Mongo DB can consists of fundamental data types namely dates, arrays, numbers, strings or the data can be augmented as sub document to the existing document. Documents are composed of field and value pairs and the structure shown below:

\{

Field1: Value1,

...

FieldN: ValueN

\}

Field can be of any data type. The document can consists of varying data types:

Var Rice S1 \{

_id: Object_id (“7098203fd5g6758ab3k98734")

Drainage: \{'Imperfectly drained"\}

Texture: \{“Clay", "silty”, "clay”, "clay loam”, "silty clay loam”\}

-...

\}

_id holds the Object_id which is unique value generated for every document. Object_id are 12 Bytes values comprising of a 4-byte timestamp value, a 5-byte random value, a 3-byte incrementing counter ${ }^{(20)}$. Mongo DB have dynamic schemas and provides flexibility to integrate the data faster and easier. The motivation of the Mongo DB language is to implement a data store that provides high performance, high availability, and automatic scaling. Mongo DB is extremely simple to install and implement ${ }^{(21,22)}$.

The given raw data provided as comma separated values (.csv) format is first loaded onto clusters of Mongo DB or the given data is augmented into the existing data. Each object stored in Mongo DB consists of location specific soil data and the climate data.

\subsection{Artificial Neural Network}

Artificial neural networks are the nonlinear mathematical learning models that are designed by simulating biological neural networks. ANNs has the ability to process the nonlinear datasets and map them with the output. Multilayer perceptrons (MLP) is most widely used ANN to solve nonlinear datasets. The network of ANN model has three main layers: input layer, hidden layer and output layer. Figure 3 shows the generalized structure of multilayer perceptron model. Finding the suitable network structure is one of the major problem faced by the researchers ${ }^{(23,24)}$. There is no systematic approach in the literature to find the structure of the neural networks. One of the basic thumb rule to choose the hidden neurons is that their number should be between the size of the input layer and the size of the output layer ${ }^{(25)}$. Researchers have adopted trial and error method to choose the hidden units and arranging these units into hidden layers until error reaches the minimum value.

Each neuron in the input layer receives the input from the user and each input signal received in broadcasted to the neurons of the hidden layer. Each unit in the hidden layer computes the output by summing up the weighted input signals and applying the activation function using equation (4).

$$
h(t)=f\left(\sum x(t) W_{H}+B_{H}\right)
$$


$W_{H}$ is the of the input unit to the hidden unit, $\mathrm{B}_{H}$ is the bias, $\mathrm{f}$ is the activation function.

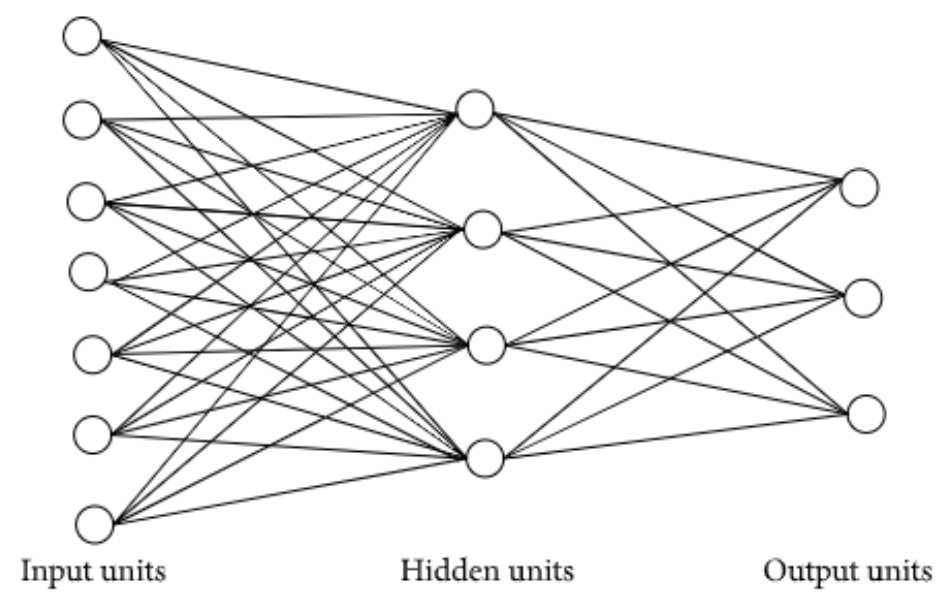

Fig 3. Structure of multilayer perceptron (5).

Each output unit sums its weighted input signal and applies its activation function to compute its output signal using equation

$$
O(t)=f\left(\sum h(t) W_{O}+B_{O}\right)
$$

Activation function used in the neural network are the mathematical equations that decide whether a neuron must be produce the output. The activation function is attached to every neuron in the network. Hence it can be considered as the gate that between the input to the current neuron and the output of the neuron. Nonlinear activation functions are required to model complex data and predict the output ${ }^{(26)}$.

RELU(REctified Linear Unit) is the most widely used activation function ${ }^{(27)}$. RELU outputs zero for the inputs lesser than zero and output one for inputs greater than zero.

Softmax function is the suitable choice for multiclass classification ${ }^{(28)}$. Softmax considered useful because it converts the scores to a normalized probability distribution. The output of the neural network passes through the softmax activation function which converts the scores into probability values which sums up to one. This can be illustrated as follows:

$$
\mathrm{Z}=[8,5,0] \rightarrow \text { Softmax layer } \rightarrow[0.9523,0.0474,0.0003]
$$

Softmax output function can be expressed as:

$$
\sigma()=\frac{e^{z_{i}}}{\sum_{j=1}^{K} e^{z_{j}}}
$$

Backpropogation algorithm is the most widely used in training multilayer perceptron neural network. It is used in feed forward networks where input signals are sent forward and errors are propagated backwards to adjust the weights in a manner to minimize the output error. During the training this process is repeated and each repetition is termed as epoch ${ }^{(29)}$. The error calculation in Backpropogation algorithm is given by

$$
E=\frac{1}{2} \sum\left(t_{k}-O_{k}\right)^{2}
$$

Each weight is updated as

$$
w_{i}=w_{i}+\triangle w_{i}
$$

Where $\Delta \mathrm{w}_{i}$ is the correction factor calculated as follows

$$
\triangle w_{i}=\eta \delta_{j} x_{i j}
$$

Where $\triangle w_{i}$ is the learning rate and $\delta_{j}$ is the difference in the output for $\mathrm{x}_{i}$ as the input.

ANN is amalgamated in agriculture sector considering its advantages over traditional decision models ${ }^{(13,30,31)}$. 


\section{Implementation}

The system is implemented using a python script running on a light weight framework known as flask over an EC2 instance. The experimental dataset consists of four sets of crop data for the crops rice, maize, sugarcane and finger millet. The dataset available is in form of categorical data. These categorical data is converted into numerical form using one-hot-encoding that enables easy implementation of machine learning algorithms. ${ }^{(32)}$ The dataset is split into training data and the test data in the ratio 60:40. Our model has 1 input layer, 2 hidden layers and a multilabel output layer. The model was trained with Backpropogation algorithm. Mean square error (MSE) was considered as the decisive parameter in to train the model. MSE is calculated as shown in Eqn. 9

$$
M S E=\frac{1}{N} \sum_{i-1}^{N}\left(T o_{i}-T r_{i}\right)^{2}
$$

Where To is the original value, $\operatorname{Tr}$ is the recommended value.

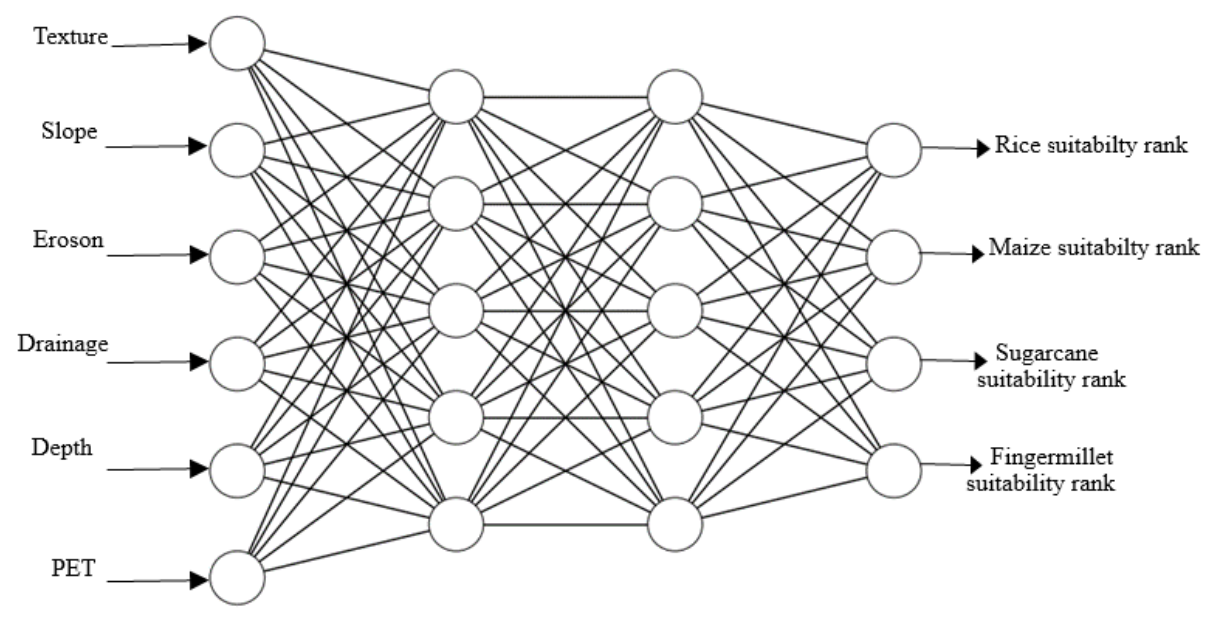

Fig 4. Neural network model used in crop recommendation framework

A four-layered ANN architecture has been proposed with the 1 input layer with 6 neurons, 2 hidden layers with 5 neurons, and 1 output layer with 4 neuron as shown in the Figure 4 . Neural networks can recognize numerical patterns, all the real world data must be converted into this numerical form. The dataset available is in form of categorical data. These categorical data is converted into numerical form using one-hot-encoding that enables easy implementation of machine learning algorithms ${ }^{(32,33)}$.

The model was trained with the back propagation algorithm. Rectified Linear Unit (RELU) activation function was used in input and hidden layers. Our system is the measure of how probable a certain crop is to grow in the given soil and weather condition. This models compares probability of crops like maize, finger millets, rice and sugarcane and ranks them according to the best choice. Hence Softmax activation function is used in the output layer. The training of ANN model was stopped after 89 epoch as the minimal MSE of .0005 was obtained.

Decision tree classifier is trained using ID3 algorithm over the same dataset. Many published works have used decision tree classifier for the recommendation model ${ }^{(11,13)}$. So decision tree is used to compare with the results obtained from the ANN.

\section{Results and discussions}

The results obtained from the model are analyzed for different crops over the same test data. The same test data is used to provide an unbiased evaluation of the model fit on the training dataset. Decision tree classifier is used over the same dataset to comparative analysis of the results obtained from ANN.

Suitability is recommended in terms of class:

1. Highly suitable-Class 1 ,

2. Moderately suitable-Class 2, 
3. Marginally suitable- Class 3,

4. Not suitable- Class 4

Tables 2, 3, 4 and 5 shows the comparishen of the original suitability values and the recommended suitability values for the crops over sample test data

Table 2. Suitability of Finger millet

\begin{tabular}{|c|c|c|c|c|c|c|c|c|}
\hline \multirow[t]{2}{*}{ Texture } & \multirow[t]{2}{*}{ Slope } & \multirow[t]{2}{*}{ Erosion } & \multirow[t]{2}{*}{ Drainage } & \multirow[t]{2}{*}{ Depth } & \multirow[t]{2}{*}{ PET } & \multirow[t]{2}{*}{$\begin{array}{l}\text { Original } \\
\text { class }\end{array}$} & \multicolumn{2}{|c|}{ Recommended class } \\
\hline & & & & & & & ANN & $\begin{array}{l}\text { Decision } \\
\text { Tree }\end{array}$ \\
\hline Sandy clay loam & $\begin{array}{l}\text { Moderately } \\
\text { slope }\end{array}$ & Severe erosion & Well drained & Deep & 8.96 & 1 & 1 & 2 \\
\hline Sandy loam & Gently slope & $\begin{array}{l}\text { Moderate ero- } \\
\text { sion }\end{array}$ & Well drained & Very Deep & 10.8 & 3 & 2 & 3 \\
\hline Sandy clay loam & Gently slope & Slight erosion & Well drained & Very Deep & 9.98 & 2 & 2 & 2 \\
\hline Loamy sand & Gently sloping & Slight erosion & Well drained & Very deep & 8.92 & 2 & 2 & 2 \\
\hline Sandy clay & Gently slopy & $\begin{array}{l}\text { Moderate ero- } \\
\text { sion }\end{array}$ & Well drained & Deep & 9.77 & 2 & 2 & 1 \\
\hline
\end{tabular}

Table 3. Suitability of Maize

\begin{tabular}{|c|c|c|c|c|c|c|c|c|}
\hline \multirow[t]{2}{*}{ Texture } & \multirow[t]{2}{*}{ Slope } & \multirow[t]{2}{*}{ Erosion } & \multirow[t]{2}{*}{ Drainage } & \multirow[t]{2}{*}{ Depth } & \multirow[t]{2}{*}{ PET } & \multirow[t]{2}{*}{$\begin{array}{l}\text { Original } \\
\text { class }\end{array}$} & \multicolumn{2}{|c|}{$\begin{array}{l}\text { Recommended } \\
\text { class }\end{array}$} \\
\hline & & & & & & & ANN & $\begin{array}{l}\text { Decision } \\
\text { Tree }\end{array}$ \\
\hline Sandy clay loam & Moderately slope & Severe erosion & Well drained & Deep & 8.96 & 2 & 2 & 2 \\
\hline Sandy loam & Gently slope & Moderate erosion & Well drained & $\begin{array}{l}\text { Very } \\
\text { Deep }\end{array}$ & 10.8 & 1 & 2 & 2 \\
\hline Sandy clay loam & Gently slope & Slight erosion & Well drained & $\begin{array}{l}\text { Very } \\
\text { Deep }\end{array}$ & 9.98 & 1 & 1 & 2 \\
\hline Loamy sand & Gently sloping & Slight erosion & Well drained & Very deep & 8.92 & 2 & 2 & 2 \\
\hline Sandy clay & Gently slopy & Moderate erosion & Well drained & Deep & 9.77 & 2 & 2 & 1 \\
\hline
\end{tabular}

Table 4. Suitability of Sugarcane

\begin{tabular}{|c|c|c|c|c|c|c|c|c|}
\hline \multirow[t]{2}{*}{ Texture } & \multirow[t]{2}{*}{ Slope } & \multirow[t]{2}{*}{ Erosion } & \multirow[t]{2}{*}{ Drainage } & \multirow[t]{2}{*}{ Depth } & \multirow[t]{2}{*}{ PET } & \multirow{2}{*}{$\begin{array}{l}\text { Original } \\
\text { class }\end{array}$} & \multicolumn{2}{|c|}{ Recommended class } \\
\hline & & & & & & & ANN & $\begin{array}{l}\text { Decision } \\
\text { tree }\end{array}$ \\
\hline $\begin{array}{l}\text { Sandy clay } \\
\text { loam }\end{array}$ & $\begin{array}{l}\text { Moderately } \\
\text { slope }\end{array}$ & Severe erosion & Well drained & Deep & 8.96 & 2 & 2 & 2 \\
\hline Sandy loam & Gently slope & $\begin{array}{l}\text { Moderate ero- } \\
\text { sion }\end{array}$ & Well drained & Very Deep & 10.8 & 2 & 2 & 1 \\
\hline $\begin{array}{l}\text { Sandy clay } \\
\text { loam }\end{array}$ & Gently slope & Slight erosion & Well drained & Very Deep & 9.98 & 2 & 2 & 2 \\
\hline Loamy sand & Gently sloping & Slight erosion & Well drained & Very deep & 8.92 & 2 & 1 & 2 \\
\hline Sandy clay & Gently slopy & $\begin{array}{l}\text { Moderate ero- } \\
\text { sion }\end{array}$ & Well drained & Deep & 9.77 & 2 & 2 & 1 \\
\hline
\end{tabular}


Table 5. Suitability of Rice

\begin{tabular}{|c|c|c|c|c|c|c|c|c|}
\hline \multirow[t]{2}{*}{ Texture } & \multirow[t]{2}{*}{ Slope } & \multirow[t]{2}{*}{ Erosion } & \multirow[t]{2}{*}{ Drainage } & \multirow[t]{2}{*}{ Depth } & \multirow[t]{2}{*}{ PET } & \multirow[t]{2}{*}{$\begin{array}{l}\text { Original } \\
\text { class }\end{array}$} & \multicolumn{2}{|c|}{$\begin{array}{l}\text { Recommended } \\
\text { class }\end{array}$} \\
\hline & & & & & & & ANN & $\begin{array}{l}\text { Decision } \\
\text { tree }\end{array}$ \\
\hline Sandy clay loam & Moderately slope & Severe erosion & Well drained & Deep & 8.96 & 3 & 3 & 3 \\
\hline Sandy loam & Gently slope & $\begin{array}{l}\text { Moderate } \\
\text { erosion }\end{array}$ & Well drained & Very Deep & 10.8 & 3 & 3 & 3 \\
\hline Sandy clay loam & Gently slope & Slight erosion & Well drained & Very Deep & 9.98 & 3 & 2 & 3 \\
\hline Loamy sand & Gently sloping & Slight erosion & Well drained & Very deep & 8.92 & 3 & 3 & 2 \\
\hline Sandy clay & Gently slopy & $\begin{array}{l}\text { Moderate } \\
\text { erosion }\end{array}$ & Well drained & Deep & 9.77 & 3 & 3 & 2 \\
\hline
\end{tabular}

The performance of the Decision tree and ANN models in the recommendation of suitable crop are measured and tabulated in Table 6.

Table 6. Accuracy values

\begin{tabular}{lllll}
\hline Model & Finger millet & Maize & Sugarcane & Rice \\
\hline Accuracy of ANN & $97 \%$ & $97.5 \%$ & $95.89 \%$ & $95.71 \%$ \\
Accuracy of Decision Tree & $96 \%$ & $90 \%$ & $92 \%$ & $88 \%$ \\
\hline
\end{tabular}

From the accuracy results, it can be concluded that ANN performs better compared to decision tree model in all the crops. So ANN can be used for effective crop recommendation with location specific soil and climatic parameters.

Figure 5 a-d shows the plot of suitability classes vs. location specific data obtained. Suitability classes plotted are obtained original values and recommended classes obtained from ANN. From the plots we can observe that accuracy obtained by ANN is satisfactory.
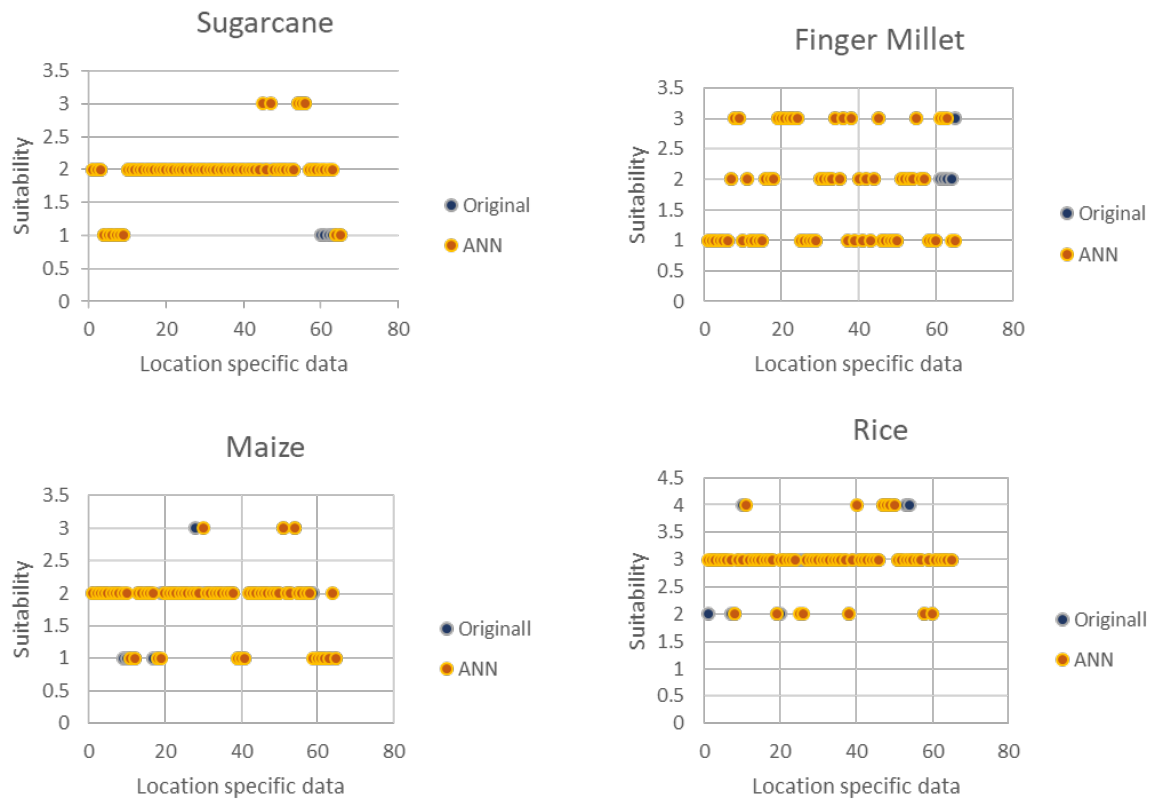

Fig 5. Suitability classes vs. location specific data 
The developed user interface takes the location and soil properties as the input as shown in Figure 6a and outputs the recommendation as shown in Figure $6 \mathrm{~b}$.

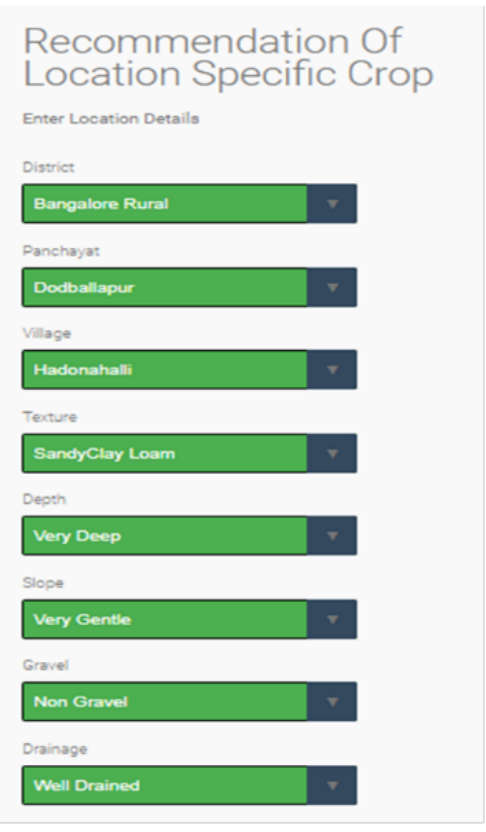

(a)

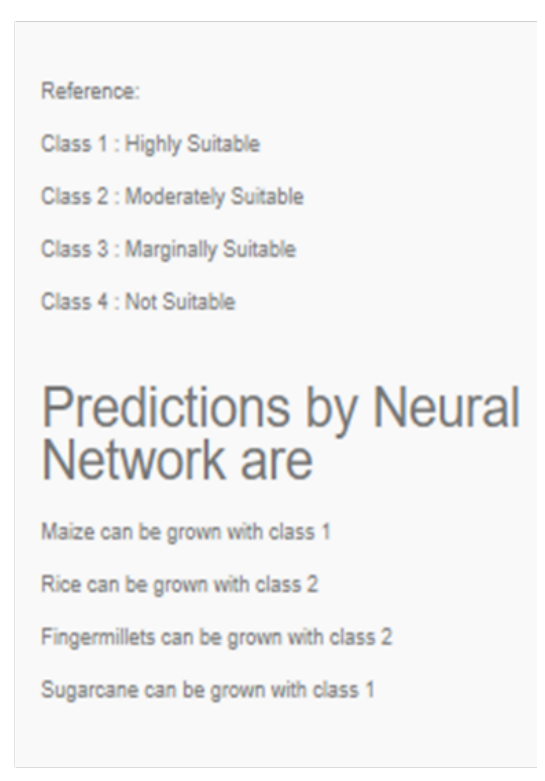

(b)

Fig 6. (a) Input form, (b) Output

\section{Conclusion}

The presented recommendation model is effective method for solving the problem faced by farmers to choose the right crop during the cropping season. The model is calibrated and tested with the data from a single region in India. The same model cannot be generalized with different soil types. Hence, there is a need to use the soil samples from different regions to generalize the model. Additionally, the model is trained with decision tree classifier to validate the performance of present model developed using ANN. With the measured accuracy values it has been found that recommendation model developed with ANN performs better with $97 \%$ accuracy compared $92 \%$ accuracy obtained from decision tree classifier. Furthermore, ANN performs better for larger datasets.

In this work a well-trained artificial neural network is used to recommend the suitable crop based on location specific soil data and historical weather data. In the future, the proposed system can be extended taking into account market demand, availability of market infrastructure, expected profit, post-harvest storage, and processing technologies. This would provide a comprehensive crop recommendation based on geographical, environmental, and economic aspects leading to successful agricultural system.

\section{References}

1) India at a glance $\mid F A O$ in India | Food and Agriculture Organization of the United Nations. 2021. Available from: http://www.fao.org/india/fao-in-india/ india-at-a-glance/en/.

2) Shankarnarayan VK, Ramakrishna H. Paradigm change in Indian agricultural practices using Big Data: Challenges and opportunities from field to plate. Information Processing in Agriculture. 2020;7(3):355-368. Available from: https://dx.doi.org/10.1016/j.inpa.2020.01.001.

3) Naidu LGK, Ramamurthy V, Challa O, Hegde R, Krishnan P. Soil suitability criteria for major crops. Nagpur, India. 2006. Available from: http: //krishikosh.egranth.ac.in/displaybitstream?handle=1/2034266.

4) Arora NK. Impact of climate change on agriculture production and its sustainable solutions. Environ Sustain. 2019;2(2):95-96.

5) Arbuckle JG, Hobbs J, Loy A, Morton LW, Prokopy LS, Tyndall J. Understanding Corn Belt farmer perspectives on climate change to inform engagement strategies for adaptation and mitigation. Journal of Soil and Water Conservation. 2014;69(6):505-516. Available from: https://dx.doi.org/10.2489/jswc.69. 6.505 . 
6) Wolfert S, Ge L, Verdouw C, Bogaardt MJ. Big Data in Smart Farming - A review. Agricultural Systems. 2017;153:69-80. Available from: https: //dx.doi.org/10.1016/j.agsy.2017.01.023.

7) Rupnik R, Kukar M, Vračar P, Košir D, Pevec D, Bosnić Z. AgroDSS: A decision support system for agriculture and farming. Computers and Electronics in Agriculture. 2019;161:260-271. Available from: https://dx.doi.org/10.1016/j.compag.2018.04.001.

8) Gaitán CF. Machine learning applications for agricultural impacts under extreme events. Elsevier Inc. 2015.

9) Crane-Droesch A. Machine learning methods for crop yield prediction and climate change impact assessment in agriculture. Environmental Research Letters. 2018;13(11). Available from: https://dx.doi.org/10.1088/1748-9326/aae159.

10) Mehnatkesh A, Ayoubi S, Jalalian A, Dehghani A. Prediction of rainfed wheat Grain yield and biomass using Artificial Neural Networks and Multiple Linear Regressions and determination the most factors by sensitivity analysis. In: Information Technology, Automation and Precision Farming. International Conference of Agricultural Engineering - CIGR-AgEng 2012: Agriculture and Engineering for a Healthier Life. 2012;p. 1554.

11) Kumar A, Sarkar S, Pradhan C. Recommendation System for Crop Identification and Pest Control Technique in Agriculture. In: 2019 Int. Conf. Commun. Signal Process. 2019;p. 185-189.

12) Pudumalar S, Ramanujam E, Rajashree RH, Kavya C, Kiruthika T, Nisha J. Crop recommendation system for precision agriculture. In: 2016 8th International Conference on Advanced Computing. 2016;p. 32-36.

13) Jha K, Doshi A, Patel P, Shah M. A comprehensive review on automation in agriculture using artificial intelligence. Artificial Intelligence in Agriculture. 2019;2:1-12. Available from: https://dx.doi.org/10.1016/j.aiia.2019.05.004.

14) Ransom CJ, Kitchen NR, Camberato JJ, Carter PR, Ferguson RB, Fernández FG, et al. Statistical and machine learning methods evaluated for incorporating soil and weather into corn nitrogen recommendations. Computers and Electronics in Agriculture. 2019;164(104872). Available from: 10.1016/j.compag.2019.104872.

15) DuraisamyVasu, Singh SK, NishaSahu, PramodTiwary, Chandran P, Duraisami VP, et al. Assessment of spatial variability of soil properties using geospatial techniques for farm level nutrient management. Soil Tillage Res. 2017;169:25-34. Available from: https://doi.org/10.1016/j.still.2017.01.006.

16) Letey J. Relationship between Soil Physical Properties and Crop Production. New York, NY. Springer. 1958.

17) Sirsat MS, Cernadas E, Fernández-Delgado M, Khan R. Classification of agricultural soil parameters in India. Computers and Electronics in Agriculture. 2017;135:269-279. Available from: https://dx.doi.org/10.1016/j.compag.2017.01.019.

18) Thornthwaite CW. An Approach toward a Rational Classification of Climate. Geographical Review. 1948;38(1):55-94. Available from: https://dx.doi.org/ $10.2307 / 210739$.

19) Kumar KK, Kumar KR, Rakhecha PR. Comparison of Penman and Thornthwaite methods of estimating potential evapotranspiration for Indian conditions. Theoretical and Applied Climatology. 1987;38(3):140-146. Available from: https://dx.doi.org/10.1007/bf00868097.

20) Documents - MongoDB Manual. 2020. Available from: https://docs.mongodb.com/manual/core/document/.

21) Jose B, Abraham S. Exploring the merits of nosql: A study based on mongodb. In: International Conference on Networks and Advances in Computational Technologies, NetACT 2017. 2017;p. 266-271. Available from: 10.1109/NETACT.2017.8076778.

22) Zhao G, Huang W, Liang S, Tang Y. Modeling MongoDB with relational model. In: 4th International Conference on Emerging Intelligent Data and Web Technologies, EIDWT 2013. 2013;p. 115-121. Available from: 10.1109/EIDWT.2013.25.

23) Zhang G, Patuwo BE, Hu MY. Forecasting with artificial neural networks:. International Journal of Forecasting. 1998;14(1):35-62. Available from: https://dx.doi.org/10.1016/s0169-2070(97)00044-7.

24) Ali Z, Hussain I, Faisal M, Nazir HM, Hussain T, Shad MY, et al. Forecasting Drought Using Multilayer Perceptron Artificial Neural Network Model. Advances in Meteorology. 2017;2017(5681308). Available from: https://doi.org/10.1155/2017/5681308.

25) Vujičić T, Matijevi T. Comparative Analysis of Methods for Determining Number of Hidden Neurons in Artificial Neural Network," Cent. Eur Conf Inf Intell Syst. 2016;p. 219-223.

26) Feng J, Lu S. Performance Analysis of Various Activation Functions in Artificial Neural Networks. Journal of Physics: Conference Series. 2019;1237(2):111122. Available from: https://doi.org/10.1088/1742-6596/1237/2/022030.

27) Ramachandran P, Zoph B, Le QV. Searching for Activation Functions. arXivorg. 2018. Available from: 1710.05941.

28) Parwez MA, Abulaish M, Jahiruddin. Multi-Label Classification of Microblogging Texts Using Convolution Neural Network. IEEE Access. 2019;7:6867868691. Available from: https://dx.doi.org/10.1109/access.2019.2919494.

29) Topuz A. Predicting moisture content of agricultural products using artificial neural networks. Advances in Engineering Software. 2010;41(3):464-470. Available from: https://dx.doi.org/10.1016/j.advengsoft.2009.10.003.

30) Song H, He Y. Crop nutrition diagnosis expert system based on artificial neural networks. In: 3rd International Conference on Information Technology and Applications, ICITA 2005; vol. 1. 2005;p. 357-362. Available from: 10.1109/icita.2005.108.

31) Chlingaryan A, Sukkarieh S, Whelan B. Machine learning approaches for crop yield prediction and nitrogen status estimation in precision agriculture: A review. Computers and Electronics in Agriculture. 2018;151:61-69. Available from: https://dx.doi.org/10.1016/j.compag.2018.05.012.

32) Using Categorical Data with One Hot Encoding | Kaggle. 2020. Available from: https://www.kaggle.com/dansbecker/using-categorical-data-with-onehot-encoding.

33) Hancock JT, Khoshgoftaar TM. Survey on categorical data for neural networks. Journal of Big Data. 2020;7(1):1-41. Available from: https://dx.doi.org/ 10.1186/s40537-020-00305-w. 